\title{
Frequency of Textual Metadiscourse Resources (MTRs) in Two Original and Simplified Novels
}

\author{
Karim Sadeghi \\ Urmia University, Iran \\ Email: k.sadeghi@urmia.ac.ir \\ Sonour Esmaili \\ Islamic Azad University, Tabriz Branch, Iran
}

\begin{abstract}
The present study was carried out to compare the use of metadiscourse textual resources (MTRs) in terms of frequency in two original novels and their simplified counterparts (i.e., Wuthering Heights and Tess of the D'Urbervilles). The researchers were interested to understand how writers of original and simplified novels made use of metadiscourse elements and whether original and simplified novels differed in the use of these resources. The corpus used in this study was analyzed based on Hyland and Tse's (2004) model. The frequency of MTRs was calculated per 1,000 words and the difference in their distribution across original novels and their simplified versions was checked using the statistical analysis technique of Chi-Square. The findings indicated that there was not a significant difference in the frequency of MTRs between original and simplified novels analyzed here, implying that the writers of both original and simplified novels strived to provide a coherent text.
\end{abstract}

Index Terms - metatexual resources, original novel, simplified novel, text analysis

\section{INTRODUCTION}

As part of teaching and learning foreign languages, written language has been regarded as a primary means of communication for several centuries; and literature has been viewed as an example of linguistic excellence, mediated mainly through written language. The elucidation and teaching of rules of language, accordingly, has been restricted to written texts (Faghih \& Rahimpour, 2009). In the last two decades, interest in the written language has been extended to almost all kinds of writing in the field of teaching foreign languages. Texts, according to Widdowson (2007), are the noticeable traces of the process of mediating a message. In conversation, these traces are disjointed and vanish quickly. They can be taped but they do not need to be, and are not usually recorded. Consequently, texts are produced by participants in spoken communication without being recorded, and their negotiation is regulated on-line. Written text, however, is recorded by the writer and is interpreted as a separate process.

Although writing is one of the principal responsibilities of academics, and no one can overlook its importance in academic life, students of EFL will especially find writing a significant but a more demanding task to master than oral skills (Marandi, 2002). Therefore, conscious awareness of the rules and conventions that govern, for example scholarly communication, is a prerequisite for both effective written and oral production and processing of academic discourse (Faghih \& Rahimpour, 2009).

One aspect of such language awareness is metadiscourse awareness which specifically refers to "self-reflective linguistic material referring to the evolving text and to the writer and imagined reader of that text" (Hyland \& Tse, 2004, p.156). According to Mauranen (1993, p.9), "through metatext, the writer steps in explicitly to make his or her presence felt in the text, to give guidance to the readers with respect to how the text is organized, to what functions different parts of it have, and to what the author's attitudes to the propositions are". According to Hyland (2005), students are often told that successful writing in English is 'reader-friendly'. It must fit together logically, be signposted to guide readers, and take their likely responses and processing difficulties into account. But it also needs to work for the writer too, as we communicate for a reason: we use language to persuade, inform, entertain or perhaps just engage an audience, and this means conveying an attitude to what we say and to our readers. These functions are collectively known as metadiscourse: the linguistic expressions which refer to the evolving text and to the writer and imagined readers of that text. Although the presence and function of metadiscourse markers has been examined in a number of different contexts, including textbooks (Hyland, 2000), student writing (Crismore, 1985), science popularizations (Crismore \& Farnsworth, 1990), advertisements and research articles (Mauranen, 1993; Hyland, 2000), surprisingly little attention has been given to the genre of literary discourse. Accordingly, this study aimed to investigate the use of textual metadiscourse resources in two original novels and their simplified versions: Wuthering Heights (WH) and Tess of the D'Urbervilles (TD). In other words, this study was an attempt to find answers to the following questions:

1. Is there any significant difference between the original version of WH and its simplified version in the frequency of use of metadiscourse resources? 
2. Is there any significant difference between the original version of TD and its simplified version in the frequency of use of metadiscourse resources?

\section{REVIEW OF RELATED LITERATURE}

\section{A. What is Metadiscourse?}

In the 1970 s, the study of texts shifted from formal aspects of writing to the organization and structuring of overall discourse. What followed was a "deeper and narrower" (Swales, 1990, p.3) approach which focused on specific genres and attempted to investigate not only formal features but also communicative aspects of written texts. By the early 1990s, linguists had begun to react against the strong emphasis on propositional meaning in text analysis. This movement resulted in a range of new perspectives on text, among which studies of metadiscourse have gained prominence. The term metadiscourse, according to Vande Kopple (2002), goes back to the work of linguist Zellig Harris in 1959 to offer a way of understanding language in use, representing a writer's or speaker's attempts to guide a receiver's perception of a text. The concept has been further developed by writers such as Williams (1981), and Vande Kopple (1985) and collects together a range of linguistic features such as hedges, connectives, and various forms of text commentary to show how writers and speakers intrude into their unfolding text to influence their interlocutor's reception of it (Hyland, 2005). The concept of metadiscourse derives from the postulate that people use language not only to convey ideational meaning, i.e. meaning based on information about the world, but that this referential meaning is complemented with other dimensions of linguistic meaning (Hempel \& Degand, 2008). In 1987 Coates criticized the fact that studies about non-referential linguistic meanings are either scarce or not given the appropriate attention: "There has been a dangerous tendency among many linguists, philosophers and semanticists to concentrate on the referential function of language at the expense of all the others" (Coates, 1987, p. 113).

Halliday tried to capture these dimensions with his concept of metafunctions of language use which express "three rather distinct and independent sets of underlying options" called macro-functions (Halliday, 1973, p.66). He claims that adult persons attempt to combine these macro-functions in all different language levels in order to express their lived experience, their relationship to the interlocutor(s), and the organization of their discourse into coherent chunks.

\section{B. Classification of Metalinguistic Devices}

Within Systemic Functional Linguistics (SFL), language is seen as being organized around and simultaneously realizing, three broad purposes or 'metafunctions' (Hyland, 2005). Halliday's (1994) macro-functions provide the most appropriate basis for classification of metalinguistic devices. In Halliday's grammatical theory, the ideational or referential function represents the external world, including not only the representation of physical experiences and internal/mental processes, such as, thoughts and feelings (the experiential subfunction, but also the fundamental logical relations that exist among these experiences and processes (the logical subfunction). The logical relations are expressed linguistically through syntactic devices of co-ordination, indirect speech, etc. The interpersonal function encompasses the relations between the addressor and the addressee in a discourse situation or speech event. Linguistically, the interpersonal function is realized through the use of first/second person pronouns and speech acts, such as, questions and directives. The textual function is concerned with the way language establishes links with itself and the situation to produce text that is linguistically cohesive and semantically coherent.

Generally, metadsicoursal comments are argued to have two main functions: textual and interpersonal. The first kind helps to organize the discourse by pointing out topic shifts, signaling sequences, cross referencing, connecting ideas, previewing material, and so on. The second kind modifies and highlights aspects of the text and gives the writer's attitude to it with hedges, boosters, self-reference, and features generally labeled as evaluation or appraisal. Broad functions are thus subdivided into more specific functions through which the writer regulates ongoing interaction and helps make the text comprehensible to a particular readership (Hyland \& Tse, 2004). Recently Hyland and Tse (2004) claimed that all metadiscoursal categories are interpersonal, therefore they proposed interactive and interactional instead of textual and interpersonal metadiscourse respectively. Hyland and Tse's metadiscourse model entails two subdivisions: Interactive resources and interactional resource. The interactional resources consist of five categories: Hedges, Boosters, Attitude markers, Self-mentions, Engagement markers. The interactive resources consist of the following categories:

1. Transitions markers: a set of devices which used to mark additive, contrastive, and consequential steps in the discourse, as opposed to the external world and help readers to interpret pragmatic connections between steps in an argument. They consist of items such as: in addition, but, thus, and, etc.

2. Frame markers: They are elements that show schematic text structure and composed of items used to sequence, to label text stages, to announce discourse goals, and to indicate topic shifts: my purpose here is to, to conclude, etc.

3. Endophoric markers: they are expression that refer to other parts of the text to make additional information available to the reader, such as: noted above, see Fig, in section 2

4. Evidentials: they are the source of information from other such as: Z states, According to X, etc.

5. Code glosses: elements that provide additional information by explaining, rephrasing or elaborating what has been said as: in other words, e.g., etc. 


\section{Key Principles of Metadiscourse}

Hyland (2005) proposes a functional model of metadiscourse. A model or theory which is based on the assumption that the rhetorical features of metadiscourse can be understood more clearly when they are used or identified in contexts in which they occur. Hence the analyses of metadiscourse have to be conducted as part of that particular context or as part of that particular community practices, values and ideas. The functional theoretical framework of metadiscourse defines writers as the conductors of interaction with the readers. The notion of the writer-reader interactions has underpinnings on the following three key principles of metadiscourse proposed by Hyland and Tse (2004):

- Metadiscourse is distinct from propositional aspects of discourse.

- Metadiscourse refers to aspects of the text that embody writer-reader interactions.

- Metadiscourse refers to relations only those are internal to the discourse. (p. 159)

The common thread in definitions of metadiscourse is that it concerns meanings other than propositional ones. Similarly Vande Kopple (1985) defines metadiscourse as 'the linguistic material which does not add propositional information but which signals the presence of an author', and Crismore (1983, p. 2) refers to it as "the author's intrusion into the discourse, either explicitly or non-explicitly, to direct rather than inform, showing readers how to understand what is said and meant in the primary discourse and how to "take" the author".. Halliday (1994, p. 70), for example, states that propositional material is something that can be argued about, affirmed, denied, doubted, insisted upon, qualified, tempered, regretted and so on. The role of metadiscourse is therefore to signal the writer's communicative intent in presenting propositional matter (Hyland, 2005).

The second principle of the model sees metadiscourse as embodying the interaction necessary for successful communication. As such it rejects the strict duality of textual and interpersonal functions found in much of the metadiscourse literature. Instead all metadiscourse is interpersonal in that it takes account of the reader's knowledge, textual experience, and processing needs and that it provides writers with an armory of rhetorical appeals to achieve this (Hyland \& Tse, 2004). If it is accepted that textual items can realize either interpersonal or propositional functions depending on their context, then there is a need of a means of distinguishing their primary function in the discourse. According to Hyland and Tse (2004), an internal relation thus connects the situations described by the propositions and is solely communicative, while an external relation refers to those situations themselves

Dahl (2004) proposes a taxonomy consisting of two categories of metatextual elements. The first, called locational metatext, comprises linguistic elements which refer to the text itself or to parts of it. her second category has been termed rhetorical metatext. It includes meta-elements which assist the reader in the processing of the text by making explicit the rhetorical acts performed by the writer in the argumentation process. Rahman (2004) labeled the function of endophoric markers as discourse entities; furthermore, he divided Hyland and Tse's (2004) frame markers into four parts: discourse acts, discourse labels, illocutionary acts and topic shifting. Rahman (2004) labeled the function of endophoric markers as discourse entities; furthermore, he divided Hyland and Tse's (2004) frame markers into four parts: discourse acts, discourse labels, illocutionary acts and topic shifting. Dafouz-Milne's textual metadiscourse resources is divided into seven categories: logical markers, sequencers, reminders that refer back to previous sections in the text, topicalizers, code glosses, illocutionary markers, and announcements that refer forwards to future sections in the text.

\section{Use of Literature in EFL Classrooms}

There were many debates over the appropriateness of using literature in second language classrooms as a source in developing reading, writing and other skills (Widdowson, 1984). Following a long period of disfavor, interest in using literature in ESL has been steadily increasing. Widdowson (1975), one of the proponents of the use of literature, points to such writing as examples of authentic use of language as discourse. Povey (1972, as cited in Harper, 1990) believes that literature will extend vocabulary and syntactic knowledge of second language learners by providing examples of language use. But this is not the case.

Some researchers criticized the use of literature for second language instruction due to the huge number of vocabulary claiming that unfamiliar content does not act as a means of understanding the writer's message but it acts as an obstacle that makes comprehension more difficult. In addition, complex syntactical structures, as well as figurative use of language, increase the complexity of reading (Harper, 1990), so the simplified version is often used instead in EFL contexts. Results of reading in both first and second language reading have demonstrated that simplification of texts may actually increase the difficulty of reading a text. Deleting explicit cohesive and rhetorical structures reduces the natural redundancy of language, forcing the reader to make inferences to compensate for missing information. Results of research reviewed in Harper (1990) have proven that in most cases the simplified versions are more difficult for students to comprehend than the original texts. In literature, form and function are closely bound: syntactic and semantic simplification may actually work against the comprehensibility of the text. As it was mentioned earlier, Hyland (2000) believes that metadiscourse is recognized as an important means of facilitating communication, supporting a writer's position, and building a relationship with an audience. Thus this work sought to investigate how original and simplified versions of novels differ in the frequency of use of metadiscourse resources.

\section{METHOD}




\section{A. Materials and Data Selection Criteria}

The data for this study came from two original English novels and two simplified versions of those novels rewritten by either a native or a non-native writer. The text type to be analyzed was therefore English novels and their simplified versions. The choice of this type of literary writing was due to their importance in developing critical reading skills, cultural knowledge of the second language and writing skills. The choice of the novels was based on a number of criteria: the first criterion was the popularity of these novels such that a person who is familiar with literature knows these novels. The other criterion was their availability in most English bookstores; and the last criterion was the existence of their simplified versions for non-proficient readers. The texts selected based on such criteria were "Tess of The D'Urbervilles" (TD) by Thomas Hardy and its simplified version by Clare West, and "Wuthering Heights" (WH) by Emily Bronte and its simplified version by Clare West. Once the texts were selected, both versions were analyzed in terms of the frequency of metadiscourse textual resources (MTRs).

\section{B. Procedures of Data Analysis}

The main objective of this study was to examine the occurrence of MTRs in two original novels and their simplified versions. To this end, the original novels and their simplified versions were divided into three sections. Since the length of original novels was much more than that of their simplified versions, and also because what was to be analyzed in both simplified and original texts should have had similar content, based on the chapters of simplified versions, corresponding chapters of original novels were identified. For instance, after the original novels were such made into chapters based on the content of their simplified versions, these texts were divided into three sections. We deemed it appropriate to divide the novels into three parts (the beginning, the middle and the ending), and the choice of which third of which pair was to be analyzed was made randomly. The second third for "Tess of The D'Urbervilles" in both versions and the last third for "Wuthering Heights" in both versions were identified for further analysis. After these divisions were made, a chapter in the relevant third was selected randomly and that chapter was analyzed for the occurrence of MTRs in both original and simplified versions. To determine the frequency of MTRs, a list of such items was compiled from Hyland (2005), Dahl (2004), Rahman (2004), Hempel and Degand (2008) and Dafouz-Milne (2008). Then they were classified into seven categories of analysis mentioned above. Some other items found in the texts were also included.

It should be mentioned again that metadiscourse is closely linked to the context in which it appears, as Hyland (1996, p. 437) strengthened this issue by asserting that "the choice of a particular device does not always permit a single, unequivocal pragmatic interpretation". As a result, the functions of all items were examined qualitatively based on their actual occurrences in context. Therefore, particular attention was paid to the context in which MTRs were used. Counting of items was conducted manually. After determining the frequency of MTRs in the identified chapters and classifying them into seven categories of analysis, the total words used in each chapter were also counted. Since the size of identified section in each original and simplified versions varied, the frequency of MTRs was calculated per 1,000 words. Inferential statistics were used to find out whether the frequency of occurrences of MTRs was significantly different in original and simplified literary texts. The analysis technique employed was Chi-square, with a significance of $\mathrm{P}=0.05$.

\section{RESULTS AND DISCUSSION}

In order to find out the differences between original and simplified novels in the frequency of use of MTRs, first, we calculated the distribution of MTRs in the identified sections of original and simplified novels, and then the frequency of MTRs was calculated per 1,000 words.

\section{A. Rhetorical Distribution of MTRs in Original and Simplified Versions of WH}

The first novel that was analyzed was Wuthering Heights: randomly the last third of this novel was identified and again randomly a part of this third was selected for analysis. In the simplified version of Wuthering Heights, chapter fifteen was analyzed that was equal to chapters twenty five, twenty six, twenty seven and twenty eight of the original novel. Table 1 presents the total number of words in the identified section, and the total frequency of MTRs in the original and simplified versions of Wuthering Heights. As it is shown in the table, the total use of MTRs in the original novel is 750 with a frequency rate of 73.15 per 1,000 words, while the total number of MTRs in the simplified version of Wuthering Heights is 110, in which the frequency rate per 1,000 words is 49.15 which is lower than that of the original one.

TABLE 1:

FREQUENCY OF MTRS IN ORIGINAL AND SIMPLIFIED VERSIONS OF WUTHERING HEIGHTS

\begin{tabular}{|l|l|l|}
\hline W H & Simplified \\
\hline \multirow{2}{*}{ Total words } & Original & 2238 \\
\cline { 2 - 3 } & 10252 & 110 \\
\hline Total devices of MTRs & 750 & 49.15 \\
\hline F Per 1,000 & 73.15 & \\
\hline
\end{tabular}

Note: $\mathrm{F}=$ Frequency, MTRs $=$ Metadiscourse Textual Resources, WH= Wuthering Heights 
Chi-Square test was used to see whether the difference between original and simplified versions of WH in the use of MTRs is significant or not. The observed value of $\mathrm{x}^{2}$ was 4.7 and which is more than its critical value:

$$
\text { Observed } x^{2}=4.7>\text { critical } x^{2}=3.84
$$

Therefore, there is a significant difference between original and simplified versions of WH in the use of MTRs and the first null hypothesis is rejected in the case of WH.

\section{B. Rhetorical Distribution of MTRs in Original and Simplified Versions of TD}

The second novel that was analyzed was Tess of the D'Urbervilles; the second third of this novel was selected randomly and in this third, chapter ten was identified in the simplified version randomly that was equal to chapter eighteen in the original one. In Table 2, the total number of words and the total frequency of MTRs in original and simplified versions of Tess of the D'Urbervilles are presented. The total frequency of MTRs in the original novel is 150 , representing the frequency rate of 53.84 per 1,000 words, whereas the total frequency of MTRs in the simplified version is 71 with the frequency rate of 46.04 per 1,000 words which is lower than that of the original novel.

TABLE 2:

FREQUENCY OF MTRS IN ORIGINAL AND SIMPLIFIED VERSIONS OF TESS OF THE D'URBERVILLES

\begin{tabular}{|l|l|l|}
\hline T D & Original & Simplified \\
\hline \multirow{2}{*}{ Total words } & 2786 & 1542 \\
\hline Total devices of MTRs & 150 & 71 \\
\hline F Per 1,000 & 53.84 & 46.04 \\
\hline
\end{tabular}

Note: F= Frequency, MTRs= Metadiscourse Textual Resources, TD: Tess of the D U'rbervilles

In order to test whether the difference between original and simplified versions of TD in the use of MTRs is significant or not, Chi-Square test was used. The result of Chi-Square test showed that the observed value of $\mathrm{x}^{2}$ is 0.6 . According to the table of critical values (Hatch \& Farhady, 1981, p. 279), critical value of $x^{2}$ for 1 degree of freedom at 0.05 level is 3.84 . Because the critical value of $x^{2}$ is greater than the observed value of $x^{2}$, the second null hypothesis is accepted.

In order to provide a definite answer to the question of whether the differences between the frequencies of MTRs in original and simplified versions of the novels studied in this research (put together) were significant or not, an average frequency (out of 1,000 words) was calculated for both original novels and for both simplified versions and then ChiSquare was used to compare the average frequencies. Table 3 displays the average frequency of MTRs in original and simplified novels.

TABLE 3:

AVERAGE F FOR ALL ORIGINAL AND SIMPLIFIED NOVELS

\begin{tabular}{ccc} 
& \multicolumn{3}{c}{ AVERAGE F FOR ALL ORIGINAL AND SIMPLIFIED NOVELS } \\
\hline & original & simplified \\
\hline F per $1,000 \mathrm{w}$ & 63.49 & 47.59 \\
\hline & Note: $\mathrm{F}=$ frequency per 1,000 words.
\end{tabular}

The observed value of $\mathrm{x}^{2}$ calculated here is 2.26 , which is less than the critical value of $\mathrm{x}^{2}$ :

$$
\text { Observed } x^{2}=2.26<\text { critical } x^{2}=3.84
$$

The result of the test indicates that differences between original and simplified novels in the use of MTRs are not statistically significant. Therefore, it can be concluded that there is no significant difference between the simplified and original versions of the novels (put together) analyzed here in terms of the frequency of use of MTRs.

\section{CONCLUSION}

This study examined the frequency distribution of MTRs in original and simplified versions of WH and TD. Thus through Chi-Square test the hypotheses was tested to see whether there is a significant difference between original novels and their simplified versions in the frequency of use of MTRs. The findings suggested that while each novel acted differently, the frequency of MTRs was almost identical in original novels and their simplified versions when both novels are taken together. This can be explained by the fact that the writers of original and simplified versions seem to be aware of the norms of writing. In the case of WH, the use of MTRs in original novel was higher than the simplified version. Chi-Square test revealed that there was a significant difference between original and simplified versions of WH in the use of MTRs. This shows that the writer of the original version of WH tends to establish more coherent text, hence providing more guidance to the reader to comprehend the text. This study also examined the overall distribution of MTRs in original and simplified versions of TD. The results showed that the overall distribution of MTRs in both original and simplified versions is identical and there is no significant difference between them in the use of MTRs and this is due to the familiarity of writers with the norms of writing. Generally, we conclude that there is not a significant difference between original and simplified novels in the use of MTRs and the difficulty in the 
comprehending of novels are not due to the lack of MTRs. And the writers in both versions tend to structure, segment and produce coherent texts.

We have been unable to identify any literature related to the analysis of literary genres in terms of MTRs. As far as other genres are concerned however, there is evidence, for example, Crismore and Fransworth (1990), that differences in text type influence the type of metadiscourse. According to Dafouz-Milne (2008), texts with a balanced number of textual and interpersonal metadiscourse are the most persuasive and texts with a low index of metadiscourse markers are less persuasive; and it seems that readers highly value texts that guide and show consideration toward the audience.

The results of the present study have obvious importance in increasing students' awareness of the way writers of original and simplified novels organize their writing. Metadiscourse is a valuable tool which provides rhetorical effects in the text such as providing logic and reliance in the text. Writers of both original and simplified novels use MTRs in their novels, so it is impossible to produce coherent texts without such resources. Metadiscoursal analysis is a useful means for the teachers to help students control their writing practices for effective writing.

\section{REFERENCES}

[1] Coates, J. (1987). Epistemic modality and spoken discourse. Transactions of the Philological Society, 85, 100-31.

[2] Crismore, A. (1985). Metadiscourse in social studies texts. Technical Report, No. 366. Urbana-Champaign: University of Illinois. Center for the Study of Reading.

[3] Crismore, A. (1983). Metadiscourse: What is it and how is it used in school and non-school social science texts. UrbanaChampaign: University of Illinois.

[4] Crismore, A., \& Farnsworth, R. (1990). Metadiscourse in popular and professional science discourse. In W. Nash (Ed.), The writing scholar: Studies in academic discourse (pp. 118-36). Newbury Park, CA: Sage.

[5] Dafouz-Milne, E. (2008). The pragmatic role of textual and interpersonal metadiscourse markers in the construction and attainment of persuasion: A cross-linguistic study of newspaper discourse. Journal of Pragmatics, 40, 95-113.

[6] Dahl, T. (2004).Textual metadiscourse in research articles: A marker of national culture or of academic discipline? Journal of Pragmatics, 36(10), 1807-25.

[7] Faghih, E., \& Rahimpour, S. (2009). Contrastive rhetoric of English and Persian written text: Metadiscourse in applied linguistic research articles, Rice Working Papers in Linguistic, 1, 92-107.

[8] Halliday, M. A. K. (1973). Explorations in the functions of language. Edward Arnold: London.

[9] Halliday, M. A. K. (1994). An Introduction to functional grammar (2nd ed.). London: Edward Arnold.

[10] Harper, C. A. (1990). A comparative study of readability and comprehensibility of a simplified and the original version of an American short story with students of English as a foreign language. PhD Thesis, Florida statement University, Florida, America.

[11] Hatch, E., \& Farhady, H. (1981). Research design and statistics for applied linguistics. Los Angeles: University of California.

[12] Hempel, S., \& Degand, L. (2008). Sequencers in different text genres: Academic writing, journalese and fiction. Journal of Pragmatics, 40, 676-693.

[13] Hyland, K. (1996). Writing without conviction. Applied Linguistics, 17(4), 433-454.

[14] Hyland, K. (2000). Disciplinary Discourses: Social interactions in academic writing. London: Longman

[15] Hyland, K. (2005). Metadiscourse: Exploring interaction in writing. London: Continuum.

[16] Hyland, K., \& Tse, P. (2004).Metadiscourse in academic writing: A reappraisal. Applied Linguistics, 25(2), 156-77.

[17] Marandi, S. (2002). Contrastive EAP rhetoric: Metadiscourse in Persian versus English. Unpublished doctoral dissertation, University of Tehran, Tehran.

[18] Mauranen, A. (1993). Contrastive ESP rhetoric: metatext in Finnish-English economics texts. English for Specific Purposes, 12, 3-22.

[19] Rahman, M. (2004). Aiding the reader: The use of metalinguistic devices in scientific discourse. Nottingham Linguistic Circular, 18, 30-48.

[20] Swales, J. (1990).Genre analysis: English in academic and research settings. Cambridge: CUP.

[21] Vande Kopple, W. (1985). Some exploratory discourse on metadiscourse. College Composition and Communication, $36,82-93$.

[22] Vande Kopple, W. (2002). Metadiscourse, discourse, and issues in composition and rhetoric. In E. Barton \& G. Stygall (Eds.), Discourse studies in composition (pp. 91-113). Cresskill, NJ: Hampton Press.

[23] Widdowson, H. G. (1975). Stylistics and the teaching of literature. London: Longman.

[24] Widdowson, H. G. (1984). Explorations in applied linguistics. Oxford: Oxford University Press.

[25] Widdowson, H. G. (2007). Discourse analysis. Oxford: Oxford University Press.

[26] Williams, J. (1981). Style: Ten lessons in clarity and grace. Boston: Scott Foresman.

Karim Sadeghi is an assistant professor of TESOL and Head at Urmia University, Iran. His publications have appeared in Asian EFL Journal, Asia Pacific Education Researcher, Modern Language Journal, Canadian Journal of Linguistics and TESL Canada Journal among others.

Sonour Esmaili is doing an MA in TEFL at Tabriz Azad University. 